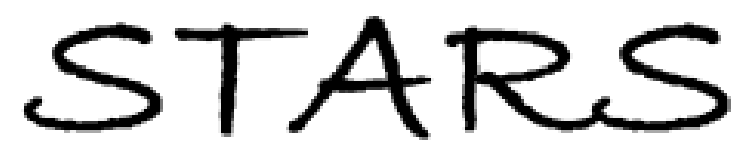

University of Central Florida

STARS

$1-1-2002$

\title{
Perdeuterated cyanobiphenyl liquid crystals for infrared applications
}

\author{
Shin-Tson Wu \\ University of Central Florida \\ Qiong-Hua Wang \\ University of Central Florida \\ Michael D. Kempe \\ Julia A. Kornfield
}

Find similar works at: https://stars.library.ucf.edu/facultybib2000

University of Central Florida Libraries http://library.ucf.edu

This Article is brought to you for free and open access by the Faculty Bibliography at STARS. It has been accepted for inclusion in Faculty Bibliography 2000s by an authorized administrator of STARS. For more information, please contactSTARS@ucf.edu.

\section{Recommended Citation}

Wu, Shin-Tson; Wang, Qiong-Hua; Kempe, Michael D.; and Kornfield, Julia A., "Perdeuterated cyanobiphenyl liquid crystals for infrared applications" (2002). Faculty Bibliography 2000 s. 3553.

https://stars.library.ucf.edu/facultybib2000/3553

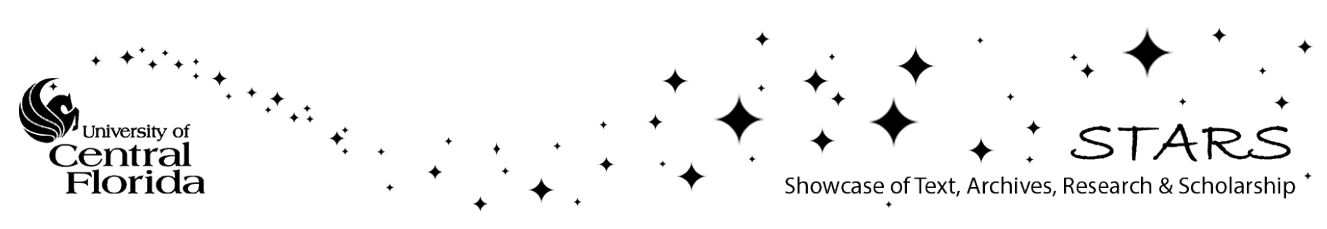




\section{Perdeuterated cyanobiphenyl liquid crystals for infrared applications}

Cite as: Journal of Applied Physics 92, 7146 (2002); https://doi.org/10.1063/1.1521512

Submitted: 26 July 2002 . Accepted: 18 September 2002 . Published Online: 27 November 2002

Shin-Tson Wu, Qiong-Hua Wang, Michael D. Kempe, and Julia A. Kornfield

\section{ARTICLES YOU MAY BE INTERESTED IN}

Infrared refractive indices of liquid crystals

Journal of Applied Physics 97, 073501 (2005); https://doi.org/10.1063/1.1877815

Electrically tunable liquid crystal lens with suppressed axial chromatic aberration

Applied Physics Letters 111, 033504 (2017); https://doi.org/10.1063/1.4985707

Electrically tunable all-dielectric optical metasurfaces based on liquid crystals

Applied Physics Letters 110, 071109 (2017); https://doi.org/10.1063/1.4976504

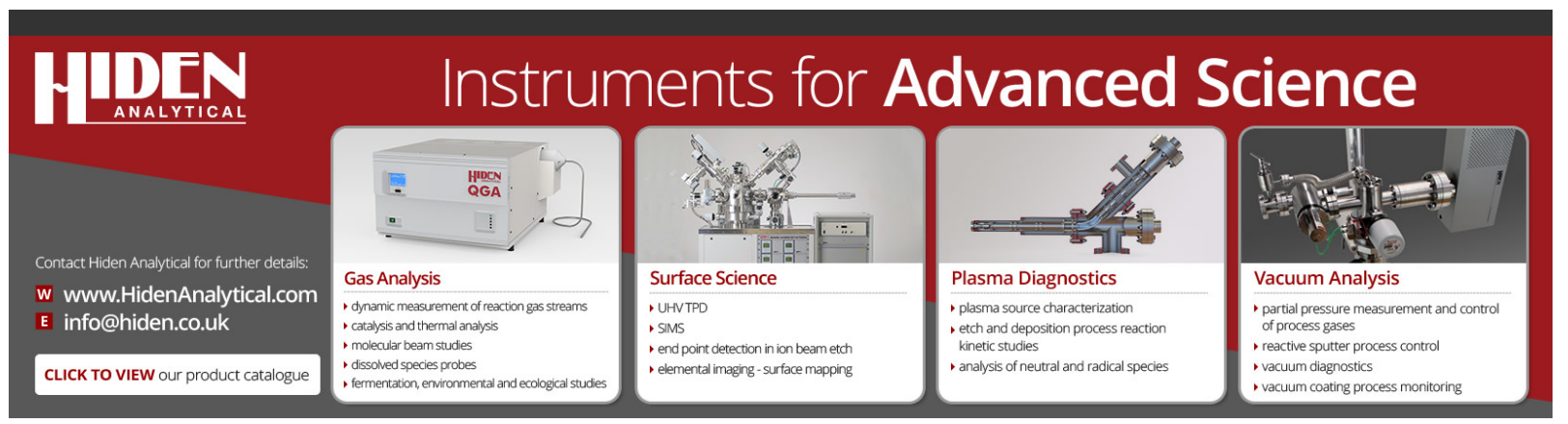




\title{
Perdeuterated cyanobiphenyl liquid crystals for infrared applications
}

\author{
Shin-Tson $\mathrm{Wu}^{\mathrm{a})}$ and Qiong-Hua Wang \\ School of Optics/CREOL, University of Central Florida, Orlando, Florida 32816 \\ Michael D. Kempe and Julia A. Kornfield \\ Chemical Engineering, 210-41, California Institute of Technology, Pasadena, California 91125
}

(Received 26 July 2002; accepted 18 September 2002)

\begin{abstract}
Perdeuterated 4'-pentyl-4-cyanobiphenyl (D5CB) was synthesized and its physical properties evaluated and compared to those of 5CB. D5CB retains physical properties similar to those of 5CB, such as phase transition temperatures, dielectric constants, and refractive indices. An outstanding feature of D5CB is that it exhibits a much cleaner and reduced infrared absorption. Perdeuteration, therefore, extends the usable range of liquid crystals to the mid infrared by significantly reducing the absorption in the near infrared, which is essential for telecom applications. () 2002 American Institute of Physics. [DOI: 10.1063/1.1521512]
\end{abstract}

\section{INTRODUCTION}

Liquid crystal (LC) optical phased arrays (OPAs) have been developed for laser beam steering, electronic lenses, and network switching. ${ }^{1,2}$ The steering angle and response time of an OPA is mainly determined by the properties of the LC material employed, such as birefringence, viscosity, and elastic constants. To steer a high power laser, the absorption of the LC cell, including the LC medium, substrates, and electrodes, plays a crucial role. The absorbed laser light is converted to thermal energy which heats the LC material. If the resultant temperature exceeds the LC's clearing point, the light modulation capability vanishes.

In the visible spectral region, most LC materials are transparent. However, in the mid $(3-5 \mu \mathrm{m})$ and long $(8-12$ $\mu \mathrm{m}$ ) infrared (IR) regions, strong molecular vibration bands exist. ${ }^{3}$ For instance, the $\mathrm{CH}, \mathrm{CH}_{2}$, and $\mathrm{CH}_{3}$ bands overlap closely in the 3.4-3.6 $\mu \mathrm{m}$ range, and the $\mathrm{CN}$ absorption band occurs at $4.45 \mu \mathrm{m}$. The overtones of these vibration bands span the near IR $(1-2 \mu \mathrm{m})$ region where $\lambda$ $=1.55 \mu \mathrm{m}$ is a primary wavelength for a telecom light switch. To clean up the 3-5 $\mu \mathrm{m}$ window, a deuterated liquid crystal is a useful approach. The deuterium (D) atom has a larger atomic mass so that the $\mathrm{CD}$ stretching occurs at a longer wavelength than that of the $\mathrm{CH}$ band. The syntheses of partially and fully deuterated cyanobiphenyl liquid crystals were reported more than two decades ago. ${ }^{4}$ Recently, perdeuteration in the side chain (not aromatic rings) of a LC compound has been accomplished. ${ }^{5}$

In this paper, we report the physical properties of a perdeuterated 4'-pentyl-4-cyanobiphenyl (D5CB) liquid crystal. The mesogenic properties of D5CB remain very similar to those of 5CB. However, its IR absorption is substantially reduced. This opens the possibility for high power laser beam steering in the near and mid IR regions.

${ }^{\text {a)} E l e c t r o n i c ~ a d d r e s s: ~ s w u @ m a i l . u c f . e d u ~}$

\section{SAMPLE PREPARATION}

The $5 \mathrm{CB}$ was obtained from Merck and used as is, but the synthesis of D5CB is briefly described below. The hydrogen atoms on 4-pentyl-biphenyl (5B) were exchanged with deuterium using a $\mathrm{D}_{2} \mathrm{O} / \mathrm{Pt}$ catalyst at a temperature of between 150 and $200{ }^{\circ} \mathrm{C}$ in a pressurized stirred reaction vessel for three days. ${ }^{6}$ This exchange was repeated eight times, obtaining $\sim 95 \%$ deuterium incorporation in 5B (D5B). Then 1 eq. $\mathrm{Br}_{2}$ was added to a solution of $\mathrm{D} 5 \mathrm{~B}$ in chloroform at 23 ${ }^{\circ} \mathrm{C}$ for $60 \mathrm{~min}$, exchanging, on the average, one aromatic deuterium for bromine, preferentially at the para position. The 4'-bromo-4-pentylbiphenyl was separated from its isomers using hexane on a silica gel column followed by recrystallization several times from hexane. Finally, the bromine atom was exchanged for a nitrile group using $\mathrm{KCN}$ with 18-crown-6-ether and a palladium triphenylphosphine catalyst in toluene at $80{ }^{\circ} \mathrm{C}$ for $20 \mathrm{~h}^{7}$ The deuterated $5 \mathrm{CB}$ (D5CB) was further purified on a silica gel column using a 50:50 hexane:dichloromethane mixture. This final purification was repeated many times, yielding fractions that were selected for purity based on their clearing point $\left(T_{c}\right)$. The final product (as shown in structure I) was D5CB with 97\% deuteration of the aromatic carbons and 89-97\% deuteration of the alkyl carbons for an overall deuteration of $95 \%$ as determined by ${ }^{1} \mathrm{H}$ NMR.

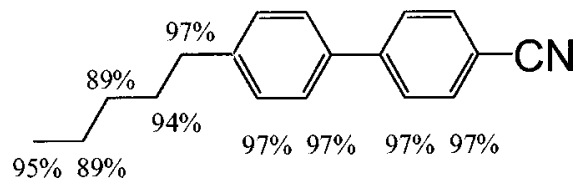

\section{PHYSICAL PROPERTIES}

We have measured the phase transition temperatures, dielectric constants, refractive indices, and infrared absorption of D5CB and compared these results with those for 5CB. 
TABLE I. Measured phase transition temperatures $\left({ }^{\circ} \mathrm{C}\right)$, dielectric constants, and elastic constants (pN) for 5CB and D5CB. $T=22^{\circ} \mathrm{C}$.

\begin{tabular}{cccccccc}
\hline \hline & Phase & $\epsilon_{\|}$ & $\epsilon_{\perp}$ & $\Delta \epsilon$ & $K_{11}$ & $K_{33}$ & $K_{33} / K_{11}$ \\
\hline 5CB & $22.5-34.2$ & 19.1 & 6.3 & 12.8 & 9.96 & 11.8 & 1.19 \\
D5CB & $21.4-32.1$ & 18.1 & 6.6 & 11.5 & 7.34 & 8.6 & 1.17 \\
\hline \hline
\end{tabular}

\section{A. Phase transitions}

The phase transition temperatures of $\mathrm{D} 5 \mathrm{CB}$ and $5 \mathrm{CB}$ were measured using a high sensitivity differential scanning calorimeter (DSC, Model TA-Q100). Results are listed in Table I. The melting and clearing temperatures of D5CB are about $1-2{ }^{\circ} \mathrm{C}$ lower than those for $5 \mathrm{CB}$. The dielectric and elastic constants were measured using a Displaytech APT-III instrument, and results are listed in Table I. D5CB has a slightly smaller dielectric anisotropy along with its lower clearing temperature. From mean field theory, ${ }^{8}$ the LC dielectric anisotropy $(\Delta \varepsilon)$ is linearly proportional to the order parameter $(S)$ which is related to the clearing temperature $\left(T_{c}\right)$ as $S=\left(1-T / T_{c}\right)^{\beta}$. For most LCs, $\beta \sim 0.25$ and is insensitive to the molecular structure. ${ }^{9}$ Thus, D5CB is expected to exhibit a slightly smaller $\Delta \varepsilon$ than $5 \mathrm{CB}$.

\section{B. Refractive indices}

The refractive indices of $5 \mathrm{CB}$ and $\mathrm{D} 5 \mathrm{CB}$ were measured at $T=22^{\circ} \mathrm{C}$ for $\lambda=546,589$, and $633 \mathrm{~nm}$ using a multiwavelength Abbe refractometer (Atago, Model DR-M4). Results are listed in Table II. Similar to $\Delta \varepsilon$, the LC birefringence $\left(\Delta n=n_{e}-n_{o}\right)$ is also linearly proportional to $S .{ }^{10}$ Thus, D5CB has a slightly smaller $\Delta n$ than does $5 \mathrm{CB}$ at all the wavelengths we studied.

\section{Infrared absorption}

The major advantage of $\mathrm{D} 5 \mathrm{CB}$ over $5 \mathrm{CB}$ is its cleaner and lower IR absorption. Two IR spectrophotometers, Perkin-Elmer Spectrum-One and Cary-500, were used for these studies. For the mid and long IR absorption measurements, two sodium chloride substrates were used. The LC cell gap was controlled at $d \sim 8 \mu \mathrm{m}$ and the measurements were made at $T=22{ }^{\circ} \mathrm{C}$ in the nematic state. In the interest of identifying the redshift originating from deuteration, we only compared their relative transmissions. The experimental results for 5CB and D5CB are shown in Figs. 1 and 2, respectively.

In Fig. 1, two major absorption bands $(\mathrm{CH}$ and $\mathrm{CN})$ occur in the $3-5 \mu \mathrm{m}\left(3300-2000 \mathrm{~cm}^{-1}\right)$ region and several absorption bands in the $8-12 \mu \mathrm{m}\left(1250-833 \mathrm{~cm}^{-1}\right)$ re-

TABLE II. The measured refractive indices for 5CB and D5CB. $T=22{ }^{\circ} \mathrm{C}$.

\begin{tabular}{ccccccc}
\hline \hline & \multicolumn{3}{c}{$5 \mathrm{CB}$} & & \multicolumn{3}{c}{$\mathrm{D} 5 \mathrm{CB}$} \\
\hline $\begin{array}{c}\text { Wavelength } \\
(\mathrm{nm})\end{array}$ & $n_{e}$ & $n_{o}$ & $\Delta n$ & $n_{e}$ & $n_{o}$ & $\Delta n$ \\
546 & 1.7336 & 1.5387 & 0.1949 & 1.7241 & 1.5386 & 0.1855 \\
589 & 1.7233 & 1.5337 & 0.1896 & 1.7140 & 1.5340 & 0.1800 \\
633 & 1.7140 & 1.5297 & 0.1843 & 1.7048 & 1.5303 & 0.1745 \\
\hline \hline
\end{tabular}

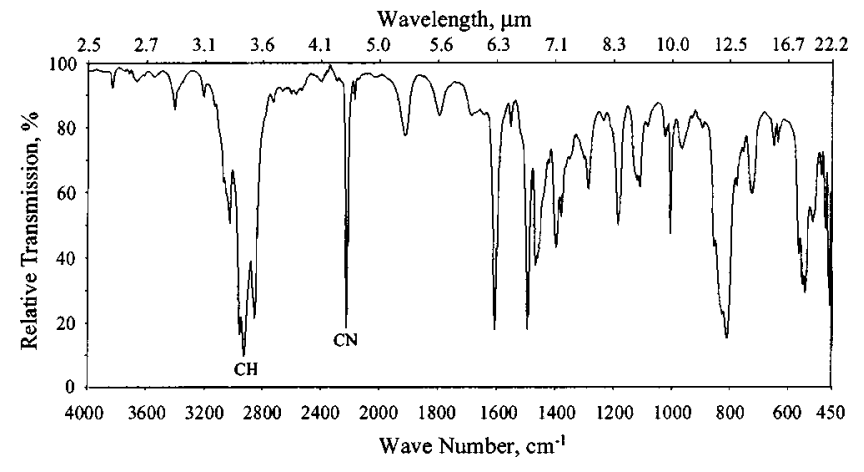

FIG. 1. Measured IR transmittance for 5CB. Cell gap $\sim 8 \mu \mathrm{m} . T=22{ }^{\circ} \mathrm{C}$.

gion. The $\mathrm{CH}, \mathrm{CH}_{2}$, and $\mathrm{CH}_{3}$ stretching vibration bands overlap closely in the $2800-3100 \mathrm{~cm}^{-1}$ range with a strong absorption intensity. In comparison, in Fig. 2, the $\mathrm{CH} / \mathrm{CH}_{2} / \mathrm{CH}_{3}$ absorption of the $95 \%$ perdeuterated D5CB is reduced substantially. The remaining absorption, centered at $\nu=2901 \mathrm{~cm}^{-1}$, is due to residual alkyl CH bonds (scheme I); the absorption due to the aromatic $\mathrm{CH}$ bonds (3000 $-3100 \mathrm{~cm}^{-1}$ ) is almost completely eliminated. The alkyl CD absorption band shifts to $\nu=2099 \mathrm{~cm}^{-1}$ which is very close to the strongly absorbing $\mathrm{CN}$ band centered at $2225 \mathrm{~cm}^{-1}$. To further remove the strong $\mathrm{CN}$ band, other polar groups such as $\mathrm{F}$ or $\mathrm{CF}_{3}$ can be considered. ${ }^{11}$ However, absorption from the aromatic $\mathrm{CD}$ stretching overlaps the $\mathrm{CN}$ stretching, which would still reduce transmission at this frequency.

Figure 1 shows some absorption in the 1800 $-2000 \mathrm{~cm}^{-1}$ range which are the overtones resulting from the aromatic $\mathrm{CH}$ bonds. In contrast, these bands are absent in D5CB. Due to the absorption frequency shift, D5CB exhibits a much cleaner and smaller absorption than $5 \mathrm{CB}$ in the 800 $-1300 \mathrm{~cm}^{-1}$ region. At $\lambda=10.6 \mu \mathrm{m}\left(\nu=943 \mathrm{~cm}^{-1}\right.$, a key $\mathrm{CO}_{2}$ laser wavelength), D5CB has a much lower absorption than does $5 \mathrm{CB}$.

Liquid crystals have been used as light switches and variable optical attenuators for fiber-optic communication at $\lambda=1.55 \mu \mathrm{m} .{ }^{12}$ A lower absorption would enable a LC device to tolerate a higher power laser beam. We have compared the absorption spectrum for D5CB with that for $5 \mathrm{CB}$ in the $1-3.2 \mu \mathrm{m}$ range. Since the absorption is relatively small in this spectral region, a 1-mm-thick quartz cell was

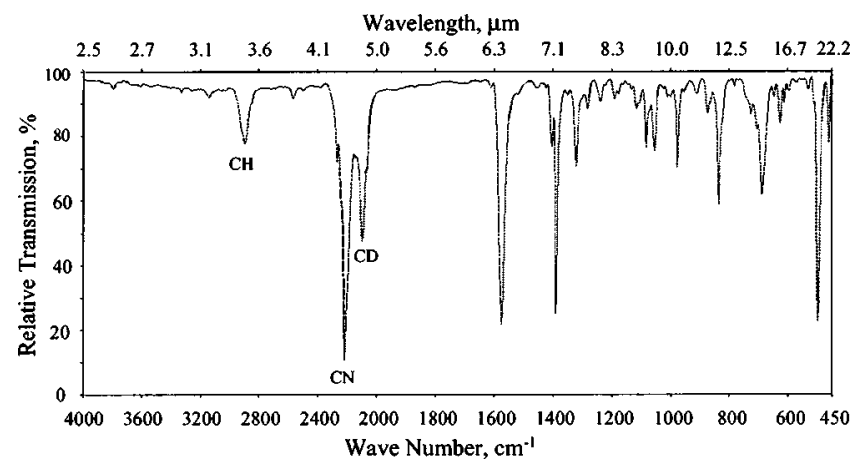

FIG. 2. Measured IR transmittance for D5CB. Cell gap $\sim 8 \mu \mathrm{m}$. $T$ $=22^{\circ} \mathrm{C}$. 


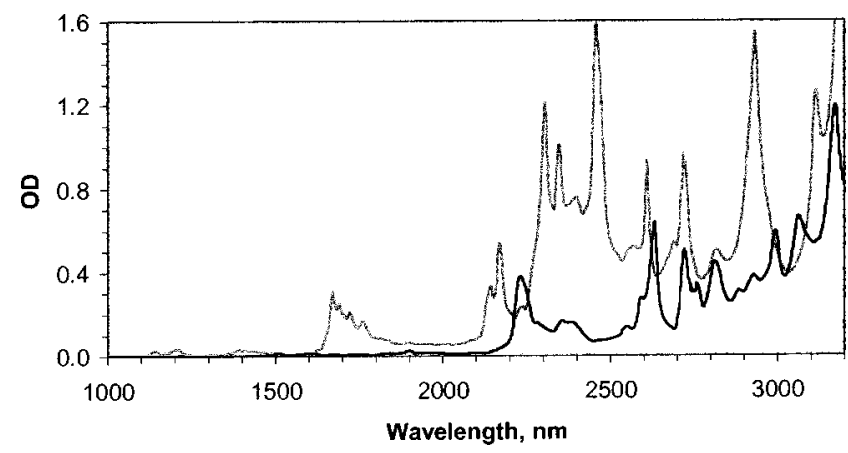

FIG. 3. Measured optical density (OD) for D5CB (dark lines) and 5CB (gray lines) in the near IR region. Cell gap $=1 \mathrm{~mm} . T \sim 50{ }^{\circ} \mathrm{C}$.

used for such experiments. For such a thick cell, it is impossible to align the LC employed. To avoid light scattering, the cell was heated to $T \sim 50^{\circ} \mathrm{C}$ so that the $\mathrm{LC}$ is in the isotropic state. The measured results are plotted in Fig. 3. The dark and gray lines represent the measured optical density of D5CB and 5CB, respectively.

From Fig. 3, it can be seen that D5CB exhibits a much lower absorption in the near IR region. Several overtone absorption bands observed in 5CB are either eliminated or significantly reduced. For example, the $\lambda=1.7 \mu \mathrm{m}$ band, which is the second harmonic wavelength of the strong $3.4 \mu \mathrm{m} \mathrm{CH}$ bands, is absent in the D5CB spectrum. Since most of the $\mathrm{CH}$ bonds in $5 \mathrm{CB}$ are replaced by $\mathrm{CD}$ bonds, the $1.7 \mu \mathrm{m}$ band no longer exists in the D5CB spectrum.

\section{Conclusion}

In conclusion, perdeuterated $5 \mathrm{CB}$ retains the major mesogenic properties of $5 \mathrm{CB}$ while exhibiting a much lower absorption in the IR region. This LC compound will extend the usable range of high power laser beam steering to the mid IR and enhance the power handling capability of LC devices for telecommunication at $\lambda=1.55 \mu \mathrm{m}$.

\section{ACKNOWLEDGMENTS}

The UCF group is supported by AFOSR under Contract No. F49620-01-1-0377. The authors are thankful to Dr. C. J. Wang and Vicky Wen for technical assistance.

${ }^{1}$ P. F. McManamon, T. A. Dorschner, D. L. Corkum, L. Friedman, D. S. Hobbs, M. Holz, S. Liberman, H. Q. Nguyen, D. P. Resler, R. C. Sharp, and E. A. Watson, Proc. IEEE 84, 268 (1996).

${ }^{2}$ P. F. McManamon, E. A. Watson, T. A. Dorschner, and L. J. Barnes, Opt. Eng. 32, 2657 (1993).

${ }^{3}$ S. T. Wu, J. Appl. Phys. 84, 4462 (1998).

${ }^{4}$ G. W. Gray and A. Mosley, Mol. Cryst. Liq. Cryst. 48, 233 (1978).

${ }^{5}$ L. Su and J. L. West, in Proceedings of the Optical Beam Steering Symposium, Kent State University, Ohio, 2000, pp. 205-210.

${ }^{6}$ A. F. Thomas, Deuterium Labeling in Organic Chemistry (AppletonCentury-Crofts, New York, 1971), Chap. 6.

${ }^{7}$ M. Prochazka and M. Siroky, Collect. Czech. Chem. Commun. 48, 1765 (1983).

${ }^{8}$ W. Maier and G. Meier, Z. Naturforsch. A 16, 262 (1961).

${ }^{9}$ S. T. Wu and D. K. Yang, Reflective Liquid Crystal Displays (Wiley, New York, 2001).

${ }^{10}$ S. T. Wu, Phys. Rev. A 33, 1270 (1986).

${ }^{11}$ S. T. Wu, J. D. Margerum, H. B. Meng, C. S. Hsu, and L. R. Dalton, Appl. Phys. Lett. 64, 1204 (1994).

${ }^{12}$ K. Noguchi, J. Lightwave Technol. 16, 1473 (1998). 